\title{
POR UMA TEORIA CRÍTICA DO DIREITO: UM ESTUDO A PARTIR DE WALTER BENJAMIN
}

\author{
For a Critical Theory of Law: A Study based on Walter Benjamin
}

Oneide Perius *

Resumo: O objetivo do presente estudo é promover uma análise dos principais movimentos argumentativos desenvolvidos por Walter Benjamin em seu estudo de 1921 intitulado Zur Kritik der Gewalt. A tarefa proposta para o artigo é a de, a partir disso, apontar a teoria crítica do direito que está sendo proposta no referido texto. Para isso serão analisados, especialmente, os conceitos de direito, justiça, mito e o polissêmico termo Gewalt.

Palavras-chave: Violência, Poder, Direito, Justiça, Walter Benjamin.

\begin{abstract}
The aim of the present study is to promote an analysis of the main argumentative movements developed by Walter Benjamin in his 1921 study entitled Zur Kritik der Gewalt. The task proposed for the article is to point out the critical theory of law that is being proposed in that text. For this, the concepts of law, justice, myth and the polysemic term Gewalt will be analyzed.
\end{abstract}

Keywords: Violence, Power, Law, Justice, Walter Benjamin.

\footnotetext{
* Doutor em Filosofia pela PUCRS. Professor de Filosofia na Universidade Federal do Tocantins (UFT). Email: oneidepe@yahoo.com.br.
}

\begin{tabular}{|c|c|l|l|c|c|}
\hline intuitio & $\begin{array}{c}\text { ISSN } \\
1983-4012\end{array}$ & Porto Alegre & Vol.11- $\mathrm{N}^{\circ} .2$ & $\begin{array}{c}\text { Dezembro } \\
2018\end{array}$ & p.05-16 \\
\hline
\end{tabular}


Avançar com o machado afiado da razão, sem olhar nem para a direita e nem para a esquerda, para não sucumbir ao horror que acena das profundezas da selva. Todo solo deve alguma vez ter sido revolvido pela razão, carpido do matagal do desvario e do mito.

Walter Benjamin

\section{Questões introdutórias}

Zur Kritik der Gewalt (1921) é um dos textos que compõem um conjunto de escritos do jovem Walter Benjamin que desconcertam a maioria dos leitores por seu caráter enigmático. A terminologia, pouco corrente no mundo da filosofia, exige uma leitura cautelosa e um árduo trabalho hermenêutico para que a força da exposição e a lógica do texto se tornem acessíveis. Portanto, seria um erro usar o clichê do enigmático como justificativa de uma leitura apressada. Um dos recursos para remediar esta dificuldade é ter em mente o panorama geral das obras do autor. A complexa teia de conceitos que perpassa o conjunto de escritos benjaminianos pode ajudar a situar mais detalhadamente o argumento central do texto em questão.

Um primeiro movimento da leitura, neste sentido, poderia ser o de situar o referido texto ante o conjunto da obra do filósofo berlinense. Neste sentido, o amplo projeto de pensar um conceito de história onde "cada segundo é a porta estreita por onde pode entrar o messias" (BENJAMIN, 1991, p.704), ou seja, onde as possibilidades de rupturas do estado de exceção tornado regra sejam tematizadas filosoficamente, pode lançar luz sobre o projeto do jovem autor de elaborar uma teoria crítica do direito. Este estudo assume, dessa maneira, uma posição interpretativa contrária a qualquer departamentalização do pensamento do filósofo. Ao contrário disso, a multiplicidade de questões e de abordagens apenas confirma a força de um pensamento cujo método é desvio, cujo caminho é na verdade descaminho, cuja orientação é perder-se. Assim, embrenhado constantemente em uma realidade que não se conforma imediatamente aos esquemas mentais que pretendem apreende-la, o filósofo percebe, nos estilhaços do presente, os elementos que permitem identificar a lógica que estrutura a realidade, bem como as potencialidades de romper e explodir essa lógica.

No texto que está sendo analisado neste estudo, este movimento do pensamento benjaminiano assume uma profundidade extraordinária. Ao tematizar em um fragmento tão curto - o original contém 24 páginas - temas tão complexos como o direito, a violência, o poder e a justiça, toda a sutileza e força desta filosofia se mostram de forma paradigmática. Para ser mais

\begin{tabular}{|c|c|c|c|c|c|}
\hline intuitio & $\begin{array}{c}\text { ISSN } \\
1983-4012\end{array}$ & Porto Alegre & Vol.11 $-\mathrm{N}^{\circ} .2$ & $\begin{array}{c}\text { Dezembro } \\
2018\end{array}$ & p.05-16 \\
\hline
\end{tabular}


específico quanto ao objetivo do estudo benjaminiano, o entrelaçamento entre os conceitos de direito e violência e a dinâmica própria como isso se realiza faz com que a crítica à violência se torne também uma crítica do direito. Como oposição à violência mítica que funda e mantém o direito, o autor apresenta a violência/potência divina ou violência pura (göttliche reine Gewalt), cuja potência destruidora e ao mesmo tempo criadora não consegue ser totalmente neutralizada e capturada para dentro do círculo estreito da ordem instituída. A soberania, em outras palavras, nunca está inteiramente atuante no interior de determinada ordem. Ela sempre se mantém externa a qualquer ordem e, desde esse lugar ou não-lugar, revela-se sempre como potência que pode destruir a ordem posta e fundar outra completamente nova.

Nesse sentido, pretende-se desdobrar a teoria crítica do direito de Walter Benjamin evitando o engano de leituras que separam sua obra em momentos e opõem, por exemplo, fase teológica e fase marxista. Isso, em nosso modo de ver as coisas, bloqueia a visão de que há uma questão fundamental que perpassa todo pensamento do autor e que, a partir de matrizes e perspectivas diversas, é abordada, qual seja, a urgência em pensar as possibilidades de romper com estruturas míticas e lógicas de violência e opressão que se naturalizaram, por exemplo, na historiografia e no direito.

Não é difícil, também, perceber a atualidade das questões que o autor propõe neste texto. A crescente juridificação das relações interpessoais nas sociedades contemporâneas está assentada sobre o pressuposto de que o direito é o mecanismo mais eficiente de resolver os conflitos e coibir a violência. A suposta neutralidade ante os conflitos conseguiria levar a uma resolução justa e seria assim capaz de interromper o círculo de violência que, sem tal interferência, contaminaria completamente a sociedade. Esta visão positiva do direito está amplamente presente tanto no senso comum como, também, em teorias e filosofias do direito. Este estudo irá acompanhar como, na contramão deste discurso, se desenvolve uma crítica filosófica do direito. Tal crítica pretende problematizar e desconstruir a visão simplista que opõe o direito e violência. Assim, o argumento central que se desenvolve no texto benjaminiano que aqui serve de referência é de que a crítica filosófica à violência terá que ser, também, uma crítica filosófica do direito.

O texto Zur Kritik der Gewalt é hoje, reconhecidamente, um clássico. Dentre muitas outras abordagens e leituras que foram feitas deste texto, podemos ressaltar as reflexões de Giorgio Agamben, Roberto Esposito, Jacques Derrida e Enrique Dussel. O fato de este pequeno

\begin{tabular}{|c|c|l|l|c|c|}
\hline intuitio & $\begin{array}{c}\text { ISSN } \\
1983-4012\end{array}$ & Porto Alegre & Vol.11- $\mathrm{N}^{\circ} .2$ & $\begin{array}{c}\text { Dezembro } \\
2018\end{array}$ & p.05-16 \\
\hline
\end{tabular}


escrito de pouco mais de vinte páginas ter despertado tão vivo interesse em autores de tamanha importância no cenário filosófico contemporâneo é certamente algo bastante curioso. Dessa forma, antes de simplesmente reconstruir os argumentos do filósofo alemão expostos no referido artigo, trata-se de explicitar o conjunto de questões extremamente relevantes que Benjamin articula neste estudo.

Inicialmente, como já foi enfatizado, pode-se perceber a complexidade do fragmento em questão destacando a teia de conceitos que o constituem. Direito, Justiça, Violência/Potência/Poder: tal é a tríade conceitual que salta aos olhos imediatamente numa primeira leitura. No entanto, cada um destes conceitos se desdobra e revela relações com muitos outros conceitos. Quando falamos em direito, por exemplo, mobilizamos as diferentes tradições do direito natural e do direito positivo. Estas diferentes compreensões do direito, por sua vez, remetem a distinções na legitimação de uma dada ordem jurídica. Uma ordem legítima é aquela que se apresenta como justa. A importância da justiça como conceito e como critério de legitimação do direito emerge neste contexto. Assim, o tema da violência e do poder entram em cena. Ou seja, uma ordem jurídica só se institui e assume concretude na história, num determinado tempo histórico. Portanto, tal ordem se afirma pela força e pela violência que permite que suplante a ordem anterior. Se a origem de determinada ordem jurídica é, desse modo, marcada pela violência, sua manutenção não o deixa de ser também. A mesma violência que institui uma ordem é, assim, aquela que, sendo constantemente exercida dentro desta ordem, tem a função de mantê-la. O poder estatal manifesto, por exemplo, na força policial, tem exatamente esta função. Ou seja, desempenha o papel de evitar a violência revolucionária, que pode desagregar a ordem, através da violência fundadora e conservadora da ordem.

\section{A dinâmica da Gewalt}

No entanto, para não permanecer no plano de uma apresentação geral e superficial do texto benjaminiano, é recomendável seguir o caminho através de seus próprios passos. Isso, neste caso específico, começa com uma análise do título. Quando Walter Benjamin propõe articular um campo semântico próprio do termo Gewalt, uma das primeiras coisas que destaca - e não poderia ser diferente para alguém que se inscreve na tradição do pensamento dialético - é o fato de que não se trata de algo natural, algo do reino da natureza. Se fosse algo natural estaríamos no plano

\begin{tabular}{|c|c|c|c|c|c|}
\hline intuitio & $\begin{array}{c}\text { ISSN } \\
1983-4012\end{array}$ & Porto Alegre & Vol.11 $-\mathrm{N}^{\circ} .2$ & $\begin{array}{c}\text { Dezembro } \\
2018\end{array}$ & p.05-16 \\
\hline
\end{tabular}


do imediato, daquilo que possui densidade própria e que se impõe ao pensamento como bloco maciço e impenetrável. A Gewalt aqui analisada não é nada disso. Gewalt, enquanto fenômeno, se constitui e é percebida no âmbito das relações. Nestes termos, o filósofo berlinense conduz o estudo por alguns campos, ainda que bastante fragmentados, para delimitar melhor a questão.

Em primeiro lugar é preciso destacar que o título do texto inicia com o conceito Kritik. Este conceito simplesmente não pode ser usado de forma leviana ou pouco refletida por nenhum filósofo depois de Kant. Desse modo, pode-se avançar bastante na hermenêutica do texto prestando atenção adequada a este conceito. Por exemplo, não estamos no terreno de uma recusa pacifista da violência quando vemos Walter Benjamin usar o termo crítica em seu título. É evidente que o filósofo, no entanto, não se opõe aos movimentos pacifistas que ainda ressoam e marcam posição desde a época da primeira grande guerra. O termo Kritik, ao invés disso, parece apontar para a delimitação de um campo próprio de análise. Trata-se de traçar as condições de possibilidade disto que se entende por Gewalt, ou seja, de perceber o campo próprio de sua constituição. Dessa forma, é um conceito no mais pleno sentido do que a tradição dialética entende por isso, isto é, é um conceito no qual se torna manifesta uma dinâmica própria da realidade. A crítica pontual do movimento pacifista ao militarismo, por exemplo, por mais importante e oportuna que seja, carece de uma análise mais profunda que trate de compreender a lógica constitutiva deste poder/violência. Do contrário permanecer-se-á no âmbito de análise de um fenômeno específico sem conduzi-lo à dinâmica onde se inscreve.

Dito isso, no entanto, é preciso avançar e se deter sobre este enigmático termo: Gewalt. As primeiras frases do texto já se apresentam como extremamente significativas para essa tarefa de uma crítica:

A tarefa de uma crítica da violência (Kritik der Gewalt) pode ser transcrita como a exposição (Darstellung) de suas relações com o direito e a justiça. Pois, qualquer que seja o efeito de uma determinada causa, ela só se transforma em violência, no sentido forte da palavra, quando interfere em relações éticas (sittliche Verhältnisse). (BENJAMIN, 1986, p.160; 1991b, p.179; tradução modificada)

Assim, pode-se avançar na exposição precisa do sentido deste termo Gewalt. E é preciso destacar que o que Benjamin pretende fazer aqui é mesmo uma exposição (Darstellung) e não uma representação (Vorstellung). Isto é, não se trata de, desde uma teoria determinada, representar o que a realidade parece ser. Ao invés disso, expor significa abrir o real e tornar visível a sua racionalidade imanente, sua lógica estruturadora. Neste sentido, pretende-se

\begin{tabular}{|c|c|l|l|c|c|}
\hline intuitio & $\begin{array}{c}\text { ISSN } \\
1983-4012\end{array}$ & Porto Alegre & Vol.11- $\mathrm{N}^{\circ} .2$ & $\begin{array}{c}\text { Dezembro } \\
2018\end{array}$ & p.05-16 \\
\hline
\end{tabular}


caminhar de modo a perceber a racionalidade deste conjunto de relações éticas e como, no escopo deste campo específico de fenômenos, o termo Gewalt revela-se um conceito adequado para explicitar sua dinâmica e racionalidade própria.

O âmbito das relações éticas (sittliche Verhältnisse) é, por si só, bastante complexo. Isto é, fundamentalmente, o que está em jogo neste conceito é o espaço da organização social, a relação dos indivíduos com a sociedade, isto é, aquela dimensão objetiva da racionalidade. Neste âmbito, pois, é que o termo Gewalt será analisado. É por isso que o filósofo poderá dizer logo na sequência do texto citado: "A esfera de tais relações é designada pelos conceitos de direito e justiça.” (BENJAMIN, 1986, p.160; 1991b, p.179). O que se estabelece desta forma, portanto, é um programa de análise. O âmbito do direito enquanto manifestação de uma racionalidade objetiva está assentada sobre uma determinada forma de Gewalt que o instaura, constitui e mantém. Dessa forma, para citar um exemplo, na Grundgesetz alemã pode-se ler no vigésimo artigo: Todo poder do Estado emana do povo (Alle Staatsgewalt geht vom Volke aus). Este âmbito das relações jurídicas, assim, é o primeiro espaço onde a dinâmica própria do referido conceito se torna visível e inteligível. Para além deste campo estrito do direito, da lei, é assinalado outro conceito que usualmente está completamente atrelado a este campo: a ideia de justiça. Ver-se-á que Benjamin romperá com a tradição que entende a ideia de justiça como consequência do direito e da lei, pois perceberá em sua dinâmica própria um descompasso em relação ao direito. A exigência posta pelo conceito de justiça é o de uma ruptura radical em relação ao círculo mítico do direito e da lei. No entanto, será necessário perceber com mais detalhe como isto se dá.

\section{A dinâmica do Direito}

No âmbito concreto do mundo do direito, Walter Benjamin começa suas considerações a partir do direito natural. Todo direito natural parte da pressuposição de uma determinada ordem natural como justa. Essa ordem legitima e justifica tudo o que está de acordo com os seus próprios fins. Portanto, toda Gewalt (enquanto poder, força, potência, violência) que for utilizada para alcançar estes fins e fortalecer a ordem posta estará justificada. Ocorre que, nesta estrutura, não pode ser encontrado nenhum critério com o qual se possa fazer uma crítica da violência, isto é, uma avaliação e consideração desde seus próprios termos. E isto pelo simples fato de que neste

\begin{tabular}{|c|c|l|l|c|c|}
\hline intuitio & $\begin{array}{c}\text { ISSN } \\
1983-4012\end{array}$ & Porto Alegre & Vol.11- $\mathrm{N}^{\circ} .2$ & $\begin{array}{c}\text { Dezembro } \\
2018\end{array}$ & p.05-16 \\
\hline
\end{tabular}


âmbito a Gewalt é um instrumento que está a serviço de fins que não podem ser discutidos, tendo em vista que estão postos. É interessante obervar como Benjamin, neste momento, fará referência à biologia darwiniana que explicita uma dinâmica natural onde a Gewalt é tornada legível como força e potência que conforma tudo para os fins desta mesma natureza. Poder-se-ia pensar, neste sentido, o alcance da naturalização da violência no âmbito daquilo que posteriormente seria chamado de darwinismo social.

O direito positivo, por sua vez, não compreende a Gewalt como elemento natural. O pressuposto desta concepção é o de que as formas de organizações sociais são constituídas historicamente e, portanto, não há uma ordem natural e justa que pudesse servir de critério para a avaliação dos meios. Se não há fins naturalmente instituídos, então é preciso estabelecer um sistema de racionalidade que garanta a correção dos meios para que, a partir deles, os fins alcançados sejam justos. Assim, a correção dos meios - e é isto que o direito positivo quer garantir - levará a fins justos.

A partir destas diferentes dinâmicas, no entanto, se pode obervar um dogma fundamental (Grunddogma) comum: meios corretos e legítimos conduzem a fins justos ou fins justos legitimam meios adequados. Ou seja, o direito estabelece um círculo perfeito. Toda Gewalt conformada a determinado modelo do que é correto e legítimo conduz à justiça. Isto é, toda ação humana concreta, que só é possível pelo fato de que há uma potência ou poder que a institui, estará absolvida de culpa e legitimada pela sua conformação à justa medida estabelecida pelo direito ou então condenada no caso de uma não conformidade. Ocorre, portanto, em qualquer um destes modelos, um movimento de captura e monopólio da violência e do poder. E isto se dá exatamente pelo fato de que todo excesso, todo poder que ultrapassa os limites postos por determinada ordem justa, já nasce culpado e condenado. Toda potência que resiste à ordem e não se conforma a ela passará a ser moralmente condenada.

$\mathrm{O}$ argumento de fundo que vai se insinuando no texto benjaminiano, assim, é uma aproximação estrutural entre o direito e o mito. No mito o ser humano se encontra sob o jugo de forças absolutas que controlam a sua vida. Qualquer hybris, ou seja, qualquer desmedida ou transgressão conduz a um destino trágico onde a culpa deverá ser expiada. A vida nasce assim sob o signo da culpa. A ideia de destino expressa isto bastante bem. Ou seja, um percurso inscrito no mais profundo da natureza determina absolutamente a vida e a reduz a um puro substrato biológico para que, exatamente, não perca de vista esta natureza determinante. A vida, assim, já

\begin{tabular}{|c|c|c|c|c|c|}
\hline intuitio & $\begin{array}{c}\text { ISSN } \\
1983-4012\end{array}$ & Porto Alegre & Vol.11 - No.2 & $\begin{array}{c}\text { Dezembro } \\
2018\end{array}$ & p.05-16 \\
\hline
\end{tabular}


não se manifesta na sua Gewalt própria, em uma ação livre, mas torna-se simplesmente o gesto de decifrar um caminho já traçado. Desde o início, portanto, a vida se estabelece na sombra deste medo e desta culpa antecipada em relação ao destino.

Neste ponto, é importante observar que Nietzsche se dedica a mostrar o erro da leitura moralizante da tragédia grega. Tanto Nietzsche como, depois, Franz Rosenzweig e mesmo Walter Benjamin, desenvolvem uma teoria da tragédia na qual esta é vista como potência desagregadora do mito. O herói trágico não é aquele que capitula ante um destino inevitável mas, do contrário, é aquele cuja vida é a luta incessante com as forças do destino que se lhe querem impor. Aliás, como bem mostrou Kant, "a tragédia grega se constituía num momento da Aufklärung, como ruptura com o mito, como “elevação" do homem ainda 'menor' e 'infantil'." (CHAVES, 2015, p.72). No entanto, ao longo da história do ocidente a potência deste enfrentamento do mito na tragédia foi se diluindo a ponto de sobressaírem uma série de leituras moralizantes desta mesma tragédia, isto é, inscrevendo-a no mesmo mito que ela pretendia dissolver.

O que vai se solidificando no mito, dessa maneira, é uma ordem natural cujo poder normalizador sobre a vida é tremendo. Todo desvio terá uma consequência imediata. O âmbito do direito, curiosamente, repete o gesto mítico de estabelecer um círculo para dentro do qual arrasta a vida em toda sua Gewalt constitutiva, prometendo-lhe um sentido e a própria redenção, isto é, a realização daquilo que esta própria ordem jurídica entende por justiça. Neste gesto acaba esvaziando a vida de sua potência constitutiva reduzindo-a a mera vida (bloßen Lebens) . A Gewalt já não será a força da vida mas a violência do mito na qual está inscrita e que lhe promete a redenção. O monopólio do poder/violência por parte do Estado, dentro de uma estrutura jurídica específica, revela exatamente isso. Esta mera vida já nasce sob o signo da culpa, pois numa ordem que determina rigidamente os seus limites esta mesma vida se desenvolve sob o jugo e o pavor destes limites. O julgamento, que em alguns casos marca o destino da mera vida, é apenas a confirmação de uma condenação que lhe é muito anterior. Afinal de contas, como já disse Kafka, “a culpa é sempre indubitável”. (KAFKA, 2011, p.88)

O direito, assim, não se afasta da esfera do mito mas, pelo contrário, para parafrasear Adorno quando escreve sobre a Aufklärung, se enreda a cada passo que dá numa nova mitologia. A existência da pena de morte como conceito limite da esfera jurídica mostra bem isso. $\mathrm{O}$ poder/violência se constitui como poder de vida e de morte. E neste momento seria bastante oportuno mostrar como em sociedades que retiraram a possibilidade da pena capital de seus

\begin{tabular}{|c|c|l|l|c|c|}
\hline intuitio & $\begin{array}{c}\text { ISSN } \\
1983-4012\end{array}$ & Porto Alegre & Vol.11- $\mathrm{N}^{\mathrm{o} .2}$ & $\begin{array}{c}\text { Dezembro } \\
2018\end{array}$ & p.05-16 \\
\hline
\end{tabular}


códigos normativos esse argumento continua válido, já que o exercício deste poder/violência como poder de vida e de morte parece, mesmo em tais casos, bastante evidente. Ou seja, a ordem posta, justificada e legitimada, acaba jogando para fora de seus limites e abandonando a sua própria sorte inúmeras vidas para as quais a morte passa a ser um destino natural. Estas mortes, por serem naturais, não impactam mais na dinâmica específica marcada pelo conceito das "relações éticas".

\section{A dinâmica da Justiça}

Desta forma, para Benjamin, é preciso identificar este caráter mítico do direito para que se possa identificar o que resta fora e não totalmente capturado e neutralizado por esta esfera. $\mathrm{O}$ termo justiça, neste sentido, será signo deste "algo" que não está contido pelo direito e, antes de ser analisado como um conceito inscrito em uma continuidade linear para com o direito, representa uma profunda ruptura. São interessantes e oportunas, neste sentido, as palavras de Ernani Chaves (CHAVES, E. 1994, p.18,19):

\footnotetext{
Sua crítica do direito, portanto, atinge dois alvos ao mesmo tempo: ela serve tanto para desmascarar a "troca enganosa" que nos faz confundir direito e justiça, quanto nossa crença de que o direito é uma elevada elaboração racional, uma conquista inelutável da "civilização", que nele nada mais há de mítico.
}

Resta mostrar, portanto, a força ou poder que, ao se subtraírem desta ordem mítica, tem a potência de desintegrá-la. Aqui adquire força o argumento benjaminiano acerca do tão enigmático e discutido conceito de violência pura ou violência divina (göttliche reine Gewalt). Como foi destacado no texto até este momento, todo poder/violência que institui ou mantém o direito se inscreve na esfera do mito. O poder que lhe resiste e que, ao final das contas, é perceptível pelo fato de que a história se move, é a potência que se lhe opõe. Isto é, impérios e sistemas jurídicos solidamente constituídos são, também eles, destituídos. Esta potência desagregadora que não se conforma a nenhum molde absoluto, essa busca obsessiva da justiça que destrói os obstáculos que se colocam pelo caminho, em outras palavras, esta pura potência revolucionária que, portanto, não quer instituir outra ordem, que não tem uma finalidade fora de si mesma: disso é que Walter Benjamin fala quando mobiliza o referido termo.

\begin{tabular}{|c|c|c|c|c|c|}
\hline intuitio & $\begin{array}{c}\text { ISSN } \\
1983-4012\end{array}$ & Porto Alegre & Vol.11 - No.2 & $\begin{array}{c}\text { Dezembro } \\
2018\end{array}$ & p.05-16 \\
\hline
\end{tabular}


Sobre esta violência/potência pura ou divina Benjamin escreve:

Deus se opõe ao mito, assim também opõe-se ao poder mítico o poder divino. Este é o contrário daquele, sob todos os aspectos. Se o poder mítico é instituinte do direito, o poder divino é destruidor do direito; se aquele estabelece limites, este rebenta todos os limites; se o poder mítico é ao mesmo tempo autor da culpa e da penitência, o poder divino absolve a culpa. (BENJAMIN, 1986, p.173; 1991b, p.199).

Deus se opõe ao mito exatamente porque não pode ser reduzido a uma imagem ou projeção humana. Ele não se deixa esvaziar de sua potência de nenhuma forma. O poder mítico que institui determinada ordem jurídica pode até utilizar uma justificação teológica para os seus próprios fins. Esta, porém, estará enredada na esfera do mito. O poder ou a violência divina é, pois, aquela que não se presta simplesmente a algum fim fora de si mesma. É a pura força de autodeterminação. Esta Gewalt se mostra, por exemplo, no paradoxo do herói trágico ao qual o destino se apresenta como inevitável e poderia, portanto, causar uma atitude resignada de aceitação. Neste caso, o poder de autodeterminação da vida reconheceria um poder superior fora de si mesma, o destino, ao qual sucumbiria. "O poder mítico é poder sangrento sobre a vida, sendo esse poder o seu fim próprio, ao passo que o poder divino é um poder puro sobre a vida toda, sendo a vida o seu fim. O primeiro poder exige sacrifícios, o segundo poder os aceita." (BENJAMIN, 1986, p.173; 1991b, p.200). O poder sangrento sobre a vida, portanto externo a ela, é o poder mítico. Este exige sacrifícios, os programa e os celebra. Tudo isso para seus próprios fins. O poder divino, por sua vez, é o poder da vida cujo fim é a própria vida.

Vê-se, assim, que a expressão violência pura ou divina (göttliche reine Gewalt) não se refere a uma esfera religiosa. Do contrário, este conceito parece apontar para todo tipo de poder ou força que esteja fora de uma perspectiva mítica, ou seja, que resista aos dispositivos de captura. É, portanto, um poder/violência que não tem nenhum fim fora de si mesmo e por isso não pode ser instrumentalizado. Não está sendo feita uma apologia deste puro poder divino pelo fato de que ele poderá ser usado para uma determinada revolução. A revolução em si, o ato de destituir um sistema de direito e instituir outro pertence à esfera do mito. A Gewalt que pode mobilizá-la e que nunca se esgota num determinado sistema de meios e fins é a pura violência divina.

\begin{tabular}{|c|c|c|c|c|c|}
\hline intuitio & $\begin{array}{c}\text { ISSN } \\
1983-4012\end{array}$ & Porto Alegre & Vol.11 $-\mathrm{N}^{\circ} .2$ & $\begin{array}{c}\text { Dezembro } \\
2018\end{array}$ & p.05-16 \\
\hline
\end{tabular}




\section{Questões conclusivas}

Torna-se necessário, na parte final deste texto, fazer referência ao motivo que justifica revisitar este texto do jovem Benjamin. Certamente, ao leitor não passou despercebida a força do argumento apresentado para uma compreensão de nossa própria época e da dinâmica que entrelaça direito, violência, mito e justiça nas sociedades contemporâneas. Parece mesmo extremamente urgente e necessária a tarefa de revolver o solo deste nosso tempo com a força da razão. Desmitificar, isto é, arrancar as máscaras de racionalidade de sistemas baseados no desvario e no mito e que escondem dinâmicas de exclusão e dominação por trás de narrativas entusiastas sobre o progresso e a universalidade do estado democrático de direito. Todo este árduo e necessário trabalho encontra no jovem autor berlinense uma fonte extraordinária.

Também é importante assinalar a originalidade da posição e do argumento benjaminiano. Talvez se explique a partir disso o interesse que o fragmento despertou em tantos importantes autores do cenário filosófico contemporâneo. Em um contexto onde a compreensão da verdadeira dinâmica das lógicas de dominação e de captura da vida para o interior dos círculos míticos era bastante precária - pode-se recordar, neste sentido, a crítica constante de Benjamin às direções do pensamento da esquerda de sua época que, por desconhecer o alcance desta lógica, acabava não conseguindo se desvencilhar de suas teias - o filósofo berlinense avança no sentido de proporcionar uma imagem bastante satisfatória da questão. E não somente isto. Ao mostrar a referida dinâmica, apontando o papel do direito, da justiça, do poder e da violência, destaca também aquilo que esta lógica não consegue neutralizar. Em outras palavras, o estado de exceção tornado regra, onde a vida deveria se conformar totalmente ao mito, não é absoluto. As fissuras, as brechas, as frestas deste círculo mítico da violência e do poder, sempre são o indício de que algo resta fora. Talvez, sejam estas fissuras que constituam a porta estreita por onde pode entrar o messias.

\section{Referências}

BENJAMIN, W. Crítica da Violência - Crítica do Poder. In: . Documentos de Cultura, Documentos de Barbárie. Escritos Escolhidos. (Seleção e apresentação Willi Bolle; Tradução Celeste H.M. Ribeiro de Sousa ... et al.- São Paulo: Cultrix : Editora da Universidade de São Paulo, 1986. p.160-175.

Über den Begriff der Geschichte. In: BENJAMIN, Walter. Gesammelte Schriften. Band I.

(Herausgegeben von Rolf Tiedemann und Hermann Schweppenhäuser). Frankfurt am Main : Suhrkamp, 1991. p.691-704.

\begin{tabular}{|c|c|c|c|c|c|}
\hline intuitio & $\begin{array}{c}\text { ISSN } \\
1983-4012\end{array}$ & Porto Alegre & Vol.11 $-\mathrm{N}^{\circ} .2$ & $\begin{array}{c}\text { Dezembro } \\
2018\end{array}$ & p.05-16 \\
\hline
\end{tabular}


. Zur Kritik der Gewalt. In: BENJAMIN, Walter. Gesammelte Schriften. Band II. (Herausgegeben von Rolf Tiedemann und Hermann Schweppenhäuser) Frankfurt am Main : Suhrkamp, 1991b. p.179-203.

CHAVES, E. Mito e Política: notas sobre o conceito de destino no "jovem" Benjamin. In: Trans/Form/Ação, São Paulo, n.17. p. 1 5-30, 1994.

. O "silêncio trágico": Walter Benjamin entre Franz Rosenzweig e Friedrich Nietzsche. In: Philosophica, n.46. Lisboa, p. 67-78. 2015.

KAFKA, F. Um artista da fome seguido de "Na colônia penal” \& outras histórias. Porto Alegre: L\&PM, 2011.

PERIUS, O. Walter Benjamin: a filosofia como exercício. Passo Fundo: IFIBE, 2013.

\begin{tabular}{|l|c|c|c|c|c|}
\hline intuitio & $\begin{array}{c}\text { ISSN } \\
1983-4012\end{array}$ & Porto Alegre & Vol.11- No.2 & $\begin{array}{c}\text { Dezembro } \\
2018\end{array}$ & p.05-16 \\
\hline
\end{tabular}

